Open Access

\title{
Written peer-feedback to enhance students' current and future learning
}

\author{
Georgeta Ion*, Aleix Barrera-Corominas and Marina Tomàs-Folch
}

\author{
* Correspondence: \\ georgeta.ion@uab.cat \\ Universitat Autònoma de Barcelona, \\ Cerdanyola del Vallès, Barcelona, \\ Spain
}

\begin{abstract}
Spanish universities are engaged in the implementation of the European Higher Education Area (EHEA). This process implies the use of the most effective instructional designs and methodologies in order to achieve deep learning, increase student involvement in their own development, and professional and personalgreater autonomy in the construction of knowledge. Peer-feedback is an effective strategy to reach such requirements. The study aimed to analyze the type of feedback students provide in peer-assessment in group work projects and to investigate students' perception towards peer-assessment for the improvement of the learning process.

The methods were mixed. A semantic analysis of the type of feedback was conducted. A total of 637 feedback units were analysed according to the guidelines developed in the project. In addition, questionnaires to students and teachers involved in the experience were administrated.

The results demonstrate that the great majority of feedback offered by students was related to task development, followed by feedback regarding the motivational aspects of the process and finally the structural and formal aspects of the writing. At the end of the process, both teachers and students declared that the feedback received helped them to better develop the task and support them in future learning.

Keywords: Assessment, Competencies, Peer-Feedback, Feedforward
\end{abstract}

\section{Introduction}

The launch of the European Higher Education Area has placed the student in the central place of the learning process. This approach has emphasised the need to align assessment activities with learning outcomes (Biggs 2003), hence the creation of continuous assessment systems where learning activities are converted into evaluation activities and evidence. However, most students' assessment activities in higher education is designed and conducted by university staff and rarely are students given central responsibility for the evaluative process (Giles et al. 2004).

Scientific literature dedicated to assessment reveals that continuous assessment aims to facilitate student learning, enables students to become active, responsible and reflective practitioners, improves the quality of learning and provides formal accountability and accreditation of knowledge (Orsmond et al. 2000; Wen et al. 2006, among others).

To address these challenges, peer-assessment has been a common practice in higher education involving an important change in assessment procedures (Patri 2002; Wen 
et al. 2006). It is defined as a way whereby students assess the quality of their colleagues' performance and give feedback to one another (Dochy, Segers, \& Sluijsmans 1999; Sluijsmans et al. 2002). It is designed to develop active autonomous learners who can think reflectively and take responsibility (Wen \& Tsai 2006). Therefore, peer-assessment is embedded in higher education to help students appraise their own work and that of others, and to adopt a more self-directed attitude towards their learning in preparation for their ongoing professional development and lifelong learning (Jaques 2000; Falchikov 2001).

As part of the constructivist approach of education, feedback is considered to be a key component of the learning and assessment activity for the reflective construction of knowledge and lies in a transformed role for students in feedback and in a variety of forms: in targeting, generating and interpreting feedback and in communicating and engaging with it (Hounsell 2007). Among the different types of procedures and methods, feedback includes qualitative comments involving groups of students or peers and has a series of strengths for students' learning, makes students more responsible for their actions, encourages a reflexive approach to learning, involves learners in judging their performance or that of their peers, and also the developing and using of evaluative expertise, and providing, seeking and utilising feedback.

Among the different types of feedback, peer-feedback appears as especially beneficial for the students' learning being eloquently articulated by Boud, Falchikov and others in a series of studies (Boud 1995; Falchikov 2001; Brew 1999), focusing on the students' involvement in the process of feedback, understanding the substantial role of feedback for higher-quality learning outcomes to be achieved. Peer-feedback is provided by equal status learners and can be regarded both as a form of formative assessment, the counterpart of teacher feedback (Topping 1998), and as a form of collaborative learning (Van Gennip, Segers, \& Tillema 2010; among others). Peer-feedback supports the learning process by providing an intermediate check of the performance against the criteria, accompanied by feedback on strengths, weaknesses and/or suggestions for improvement (Falchikov 2001).

The use of peer-feedback is justified from different perspectives: Askew and Lodge (2000) focused on the constructivist theories of learning where feedback is able to engage both teacher and students in a reflexive and collaborative dialog. As assessees, students receive feedback and may make improvements accordingly. Through such processes, peer feedback becomes a strategy for formative assessment and a tool for reflection by students (Cheng \& Warren 1999). But, not all feedback leads to performance improvement. Nicol and Macfarlane-Dick (2006) focused on self-regulation in learning which led to the drawing up of a set of principles for a good feedback practice. These authors highlight the students' capacity to self-regulate their learning which can be powerfully facilitated through well-designed feedback and formative assessment and can empower students to generate their own internal feedback in an effective way.

In addition, recent research at universities also demonstrates that the proactive feedback called feedforward (Carless et al. 2006; Boud \& Molloy 2013) tends to be more useful in order to enhance students' self-regulation and stimulate the learning process. All these perspectives define an authentic and significant engagement in and with feedback as a condition for sustainability in students' learning. Strijbos et al. (2010) add several conditions under which proactive feedback has a positive influence on future learning. This is focused on the type of writing (mostly syntactic and grammatical) which 
feedback should provide. In the same line, the proposal of Lilly et al. (2010) is more generic and focuses on three aspects: content, style and clarity and so offers clues as to how feedback has to be with respect to these three axes. The proposal of Nicol (2011) is even more generic or wide, for who written feedback should fulfil some formal characteristics regarding the way in which it is presented but also some characteristics which are much more general, with respect to the purpose, frequency, content, specificity of the feedback that is provided. Nicol proposes a type of feedback that is easy to understand, comprehensive, flexible, contextualised, among other characteristics.

As can be appreciated, some recurring aspects which improve the efficacy of feedback are: sufficient time should be allowed for it; that it should be specific (as demonstrated by Strijbos et al. 2010); and it must be positive and constructive (Shute 2008). There are also recurring aspects with respect to format, clarity, specificity, precision and dimension.

Starting from this background, our research aims to analyse the type of feedback students provide in peer-assessment in group work projects, to investigate students' perception towards peer-feedback for the improvement of the learning process and finally to give suggestions to promote the effective use of peer -assessment in educational programs.

Specifically, the study addresses the following questions:

1. What type of feedback students provide to their peers?

2. What are the benefits of using peer assessment in education from the students and teachers' perspective?

3. What are the shortcomings of using peer assessment in education field from the students and teachers' perspective?

\section{Methods}

In order to accomplish these objectives, exploratory research was conducted between September 2014 and June 2015, among a non-random sample of 160 students from the Autonomous University of Barcelona (UAB) undergraduate programmes in Pedagogy and Social Education. ${ }^{1}$ The participants were all the students involved in the subject titled: "Organisation and groups" which was imparted in the second year. During the course students have been involved in an experience based on the use of peer-assessment. During this process, students provided peer-feedback to their colleagues. Firstly they rated and commented on two randomly assigned peers' projects, and secondly they were then asked to improve their projects based on the feedback they received. Feedback has been provided in written form, on an academic assignment, using track changes mode of word. In order to implement this task, students received at the beginning of the course specific guidelines on how they have to provide feedback, what kind of feedback they could provide and also they have been trained on the procedure.

At the end of the experience a guideline for the analysis of feedback has been designed. Data was also collected through the administration of two questionnaires: one for students and another one for teachers.

Firstly, data was gathered through the analysis of the content of the feedback provided by peers. For that purpose, a guideline of analysis have been designed based on the proposal of Nicol (2011) which evaluated the feedback through the following categories:

(1) Task development: 
a) feedback is centred on the objectives of the task,

b) feedback is oriented towards the learning results,

c) feedback could be transferred to other learning tasks or other practical activities,

d) feedback is balanced between the negative and positive aspects of the assignment,

e) feedback enhances students' reflection,

f) feedback stimulates the students' implication and engagement with the task,

g) feedback refers to the students" competencies.

(2) Formal aspects:

a) language correctness,

b) structural aspects of the assignment,

c) use of norms of written communication,

d) ability to produce changes.

(3) Motivational aspects:

a) feedback is able to motivate and improve students' self-esteem

b) assertiveness

Each one of these indicators is evaluated with a Likert scale from 1 (less) to 4 (a lot).

The guideline was validates and piloted by the research team and experts and improvements were made on the first version during the process.

This guideline permitted the identification of "feedback units" (the comments with sense elaborated by students in the feedback process). These units were evaluated with the indicators established in the guideline. At the end of the process, all 160 students provided a total of 637 feedback units.

Data gathered through semantic analysis was completed with information obtained through two questionnaires: one for the teachers and the other for the students. Both questionnaires contained closed items, in which each item had to be evaluated in a scale of 1 to 4 . The participants could also freely express their opinion in an open section of the questionnaire. These questionnaires were validated through experts' validation

Both questionnaires contain items organised around following aspects:

a. Satisfaction in relation to the activity: satisfaction with regard to the frequency of the feedback, to the workload, to the training received at the beginning of the activity

b. Aspects related to the feedback received: feedback helps to develop competencies, to enhance the learning process, to improve future learning, to improve engagement with learning

c. Aspects related to the feedback provided: feedback helps to develop competencies, to enhance the learning process, to improve future learning, to improve engagement with learning.

All 160 students involved in the experience have answered the questionnaire at the end of the process. In addition, all four teachers in charged with the subject completed the questionnaire.

\section{Results}

In spite of the initial exploratory nature of the study, the results presented in this paper include referential statistics to try to reach conclusions beyond the immediate data 
alone. The results of the analysis of the frequencies of the data grouped in function of the profile of the participants (students and teachers) of the study are presented, as well as the semantic analysis of the qualitative responses obtained in the final evaluation questionnaires that both collectives responded to.

The results are divided in two main sections: on the one hand, a descriptive analysis of the type of feedback that the students have given to their colleagues; and on the other hand, the data of the questionnaires of the students and teachers on their experience of peer-assessment developed in the classroom.

\section{Typology of feedback}

Through an analysis of the units of feedback provided by the students, three types of feedback have been identified corresponding to the three types of regulation described by Nicol (2011) within the theoretical framework. These types are: feedback oriented towards the task; that oriented towards motivational and emotional aspects; and the feedback regarding structural aspects of the activity.

With respect to the first type of feedback, $54 \%$ of the units of analysis made reference to indicators related with the task, $25 \%$ was linked to indicators related with motivational and emotional aspects and the remaining $21 \%$ to aspects linked to the structure of the task.

The types of feedback for each one of these categories were distributed in the following way: in the case of feedback that is task-oriented, we note that the bulk of the feedback is related to the learning results linked to the task $(n=285)$, followed by feedback regarding the objectives of the task (relevant: $n=273$ ), feedback that fosters reflection and the processes of self-regulation $(n=228)$, feedback that makes reference to the level of implication of the students in the task $(n=218)$, followed by feedback enabling transfer to other tasks $(n=213)$. Finally, the feedback is balanced in that it refers to both positive and negative aspects of the task $(n=208)$ and makes reference to the acquisition of competencies $(n=185)$.

As regards the second category of feedback, which refers to structural elements, we note that most of the feedback encourages the receivers to make changes in their work $(n=207)$, followed by the feedback oriented towards the structure of the work $(n=205)$ and the use of drafting standards and finally, linguistic correction. The third category of feedback, regarding motivational aspects, highlights the texts which reinforce self-esteem $(n=323)$, followed by those that make use of assertiveness to stress the importance of the positive or the negative aspects in the accomplishment of the activity $(n=286)$.

The distribution of the different types of feedback is illustrated in Fig. 1.

\section{Students' perceptions about peer-assessment}

When the activity ended, the students were requested to answer the questionnaire to measure their perceptions in relation to three groups of variables: (1) general perception regarding the accomplished activity; (2) evaluation of feedback received; and (3) evaluation regarding the intention of the feedback offered.

Whole participants, both students and teachers have expressed their satisfaction with the experience of peer-feedback and they consider that this has helped them to improve the learning process. 


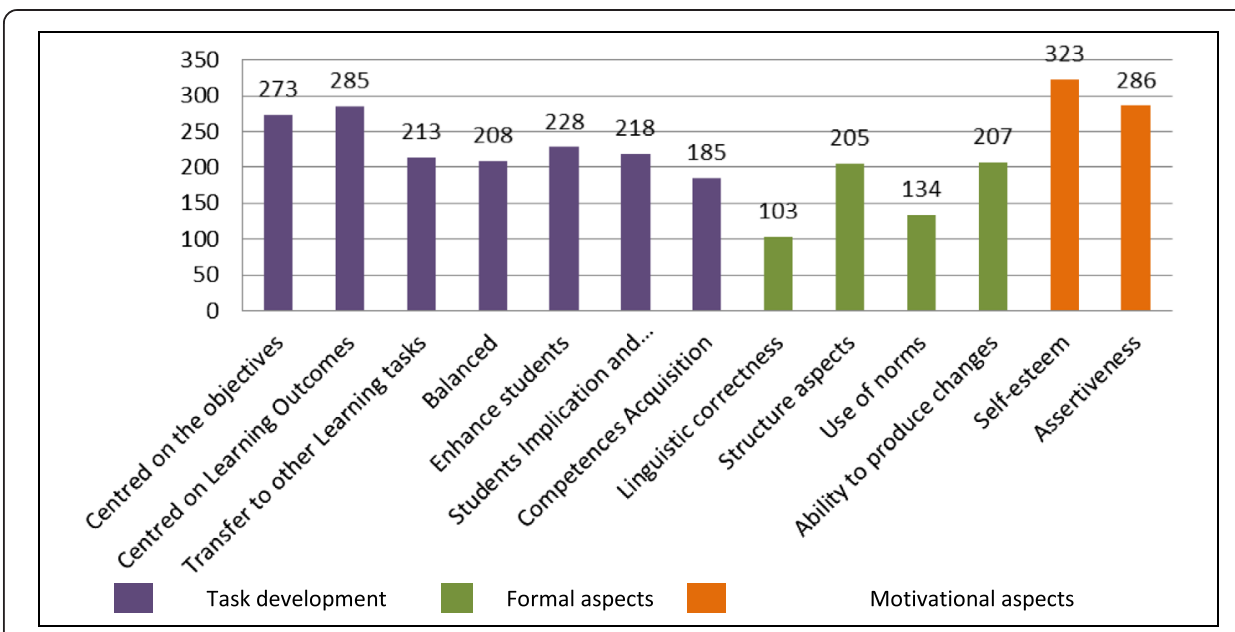

Fig. 1 Distribution of the units of feedback according to the indicators of the framework of analysis

From the general perception of the students (Table 1), it can be observed that all the aspects considered have received a very positive assessment, above 2 of a scale of 1 to 4. The participants consider that the feedback has helped them to improve on their future tasks (feedforward) with a score of 3,14, and it has helped them to increase their level of implication in their learning $(3,03)$, followed by the perception that the activity has helped them to improve their competencies $(2,97)$.

The proactive role of feedback in the enhancement of future tasks has been highlighted by the participants in the open-ended section of the questionnaire. They point the fact that the feedback received has been useful given because it permitted them to: know how to rectify thanks to the help provided by others (Group 1). It has helped them not only to accept constructive criticism, but also to know how to do their work better in the future (Group 2).

With regard to the second most valued aspect linked to a better involvement of the students with the activity that they are developing, the opinions of the participants emphasise this aspect: "Being able to evaluate all the members of the group so that the participation and implication of all of them are reflected (Group 3).

Table 1 Perception of the teachers and students in relation to the usefulness of the feedback

\begin{tabular}{lll}
\hline Items & $\begin{array}{l}\text { Students' perception } \\
\text { (means) }\end{array}$ & $\begin{array}{c}\text { Teachers' perception } \\
\text { (means) }\end{array}$ \\
\hline $\begin{array}{l}\text { Feedback has helped to enhance the competencies of the } \\
\text { student. }\end{array}$ & 2,97 \\
$\begin{array}{l}\text { Feedback has helped to improve the learning process of the } \\
\text { student. }\end{array}$ & 2,86 & 2,5 \\
$\begin{array}{l}\text { Feedback has been useful to improve the future activities of } \\
\text { the student. }\end{array}$ & 3,14 & 2 \\
$\begin{array}{l}\text { Feedback has increased the motivation of the student. } \\
\text { Feedback has heightened the involvement of the student in }\end{array}$ & 3,03 & 3 \\
the activities. & 2,61 & 2 \\
The frequency of the Feedback has been appropriate. & 2,53 & 2,5 \\
The workload for the student has been acceptable. & 2,64 & 2,5 \\
The workload for the teachers has been satisfactory. & & 3 \\
\hline
\end{tabular}


Thirdly, the enhancement of competencies linked to the subject is positively valued. Regarding to this aspect, the students also highlight it as one of the most positive points of the activity carried out, confining it principally to the learning that is produced between peers:

Learning about ourselves, without the pressure of knowing that there is an evaluator that has assessed you. Feedback between colleagues produces horizontality, permitting proximity, trust and a greater comprehension and development of the competencies required (Group 4).

The aspect with the lowest evaluation is related to the frequency of the feedback that the students have received, obtaining a score of 2,53 . This could be linked to the delay of some groups in forwarding their scores of feedback to their colleagues, and the consideration that they would have been more useful if they were returned in good time in order to introduce changes in the work to be undertaken.

Perhaps the weakest point has been the timing of the return of feedback (Group 5).

If we contrast this block of items with the opinion of the teachers, we can see that the results coincide, although the students tend to evaluate all the aspects at a higher level. The teachers coincide that the feedback has contributed to improve the future activities of the students (mean of 3 out of 4 ) and it has helped them to increase their participation and engagement. On a second level, the assessments are found with respect to the usefulness of the feedback to enhance the competencies of the students, to improve the learning process $(2,5)$ and finally it was assessed that the feedback has contributed to boost the motivation of the students in the activities (2 out of 4). Just as for the case of the students, the teachers coincide that the weak point of the experience has been the frequency of the feedback ( 2 out of 4 ). Table 1 systematises the information relative to the usefulness of the feedback according to the perception of the teachers and the students.

The results obtained in the aspects concerning the assessment of feedback received on the part of the participants, as well as the assessment of their intentionality with those that offered feedback to the rest of the colleagues that participated are outlined in Fig. 2. The first aspect that can be highlighted is the tendency of the students to appraise markedly higher the evaluations that they have offered to the rest of the students in all the indicators posed.

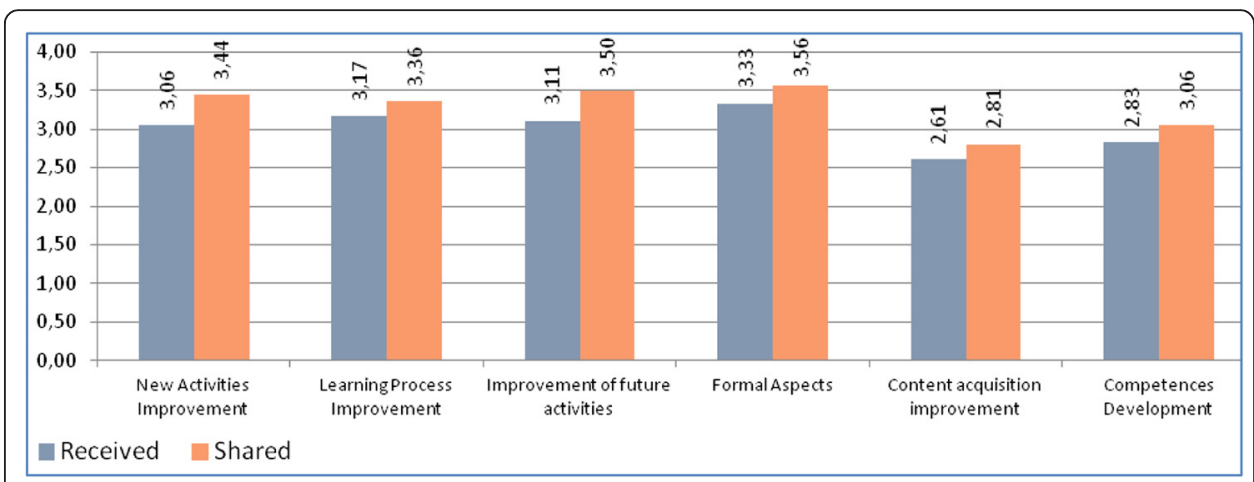

Fig. 2 Average scores of the feedback received and shared 
The one that scored highest in both cases is the one which is linked to the formal aspects of the task (drafting, orthography, presentation, linguistic correction, style etc.), which receives a mean score of 3,56 in that offered, and 3,33 in what is received. Hereafter, we can see that a score of 3,50 appears for feedback offered, and 3,11 for feedback received. The capacity of the indications to motivate to keep working and improve future activities, an aspect that is related with feedforward, together with an enhancement of future activities, receives a score of 3,44 in the feedback that is offered, and 3.06 in the assessment of what is received. These two aspects, which are placed in second and third place respectively, are related with the factor which the students have appreciated most of the experience, linked to the capacity of feedback received to enhance future activities.

The improvement of the learning process appears to be rated in fourth place in the feedback offered (3,36 points on average), and in second place in the feedback received (3,17 points), and this would be linked to the units of feedback analysed, $54 \%$ of which is related to the task. The item with the lowest score is related to the capacity of the feedback to foster a greater knowledge of the specific content of the subject, which received a score of 2,81 in the feedback offered, and 2,61 in the feedback received.

Finally, the open responses of the students underline the potentialities and the points to be improved with regard to feedback. Among the positive evaluations of the experience, aspects that are linked with peer-learning are emphasised, as well as selfreflection of the actual activity and learning.

The strong point is the acquired horizontal learning, integrating different points of view (Group 7).

Among the negative evaluations of the experience, besides the lack of time to introduce changes once the feedback of the colleagues is received, aspects not directly related to the experience of feedback carried out are emphasised, like those of the lack of collaborative working in the team and the low level of involvement of some students.

Regardless of the quantity of feedback received, if we are not in a cohesive group and that we don't all collaborate together, it will be difficult to resolve the activities correctly (Group 10).

\section{Discussion and conclusions}

The results of the study demonstrate the role of peer-feedback in the students' learning process. Students were involved in an active way in the feedback process with their peers, declaring that through this process they learned not only how to better solve their tasks but also how to solve similar tasks in the future. This proactive feedback called feedforward has a high potential to enhance students' self-regulation and stimulate the learning process (Carless et al. 2006; Boud \& Molloy 2013) and define authentic and significant engagement in and with feedback as a condition for the sustainability in students' learning.

In relation to the types of feedback, as we have observed, feedback offered during the process is mainly oriented to task solving and is characterised by the information on how to improve work and how to take learning further. This proactive dimension of the feedback associated to the self-regulation of learning facilitates students' learning and help them to become active, responsible and reflective practitioners, improve the 
quality of learning and provide formal accountability and accreditation of knowledge (Wen et al. 2006; Shute 2008). This approach certainly reinforces the positions of many authors, like that of Nicol and MacFarlane-Dick (2006), who defend the formative dimension of feedback in the teaching and learning process, and specifically, for assessment purposes.

The motivational role of the feedback is also an important component in the regulation process. The results show the feedback is characterized by the emotional elements which stimulate the implication of students, in line with Kimbell and Stables (2008) studies that highlight the importance of the support offered to students in order to increase their level of responsibility for their own learning and autonomy.

The research results also demonstrate the high level of satisfaction for both teachers and students with peer-feedback. Students and teachers agreed that feedback helps students to better learn and develop their competencies. In addition, it helps them to get engaged with the learning process and to increase their self-regulation abilities.

Comparing the students' perception through the questionnaires on the intention of their feedback and the perception on the usefulness of feedback received, the results are coherent. They give a critical role to the feedback for future activities, and to feel motivated to continue studying and to improve their learning. These results are also confirmed by the semantic analysis of the feedback units. Moreover, comparing to the type of feedback students really provide, we can observe some divergences. While students perceive feedback they provide is oriented to improve structural aspects of the task, analysing the feedback provided to their colleagues demonstrates that the main type of feedback is oriented to the improvement of task solving. This situation needs further clarification in the future in spite studies as carried out by Simpson and Clifton (2015) reached similar results showing the feedback developed during the peer review process is focused on style and presentation preferentially to content.

The data reveals that students and teachers are highly satisfied with the peerfeedback in the assessment process. The horizontal learning, motivation and implication make students more aware of their learning process represent their arguments supporting the strong points of peer-feedback in order to make it positive and constructive (Shute 2008). The critical points which should be improved are related to the time delivery of the feedback that is too slow in some cases, the amount of work and the difficulties teachers experiment to monitor the changes in the revised task. All these weak points should be improved in order to ensure an authentic and sustainable learning as demonstrated by Strijbos et al. (2010).

In short, the results of the research suggest the benefits of transferring the protagonist role from the teachers to the students in search of a more dialogic feedback, in which students are the judge of their own learning process (Orsmond et al. 2000; Boud \& Molloy 2013) and changing the attention of the teachers (as the only ones that offer feedback) towards the students and what they can do (Ruegg 2015).

This has led us to propose future projects of educational innovation and research, analysing in depth the peer-feedback process where students are involved, in which they have a more active role in the processes of feedback and this being self-regulated and dialogic and evidently implicating that the student is involved, knows and applies the standards of work, utilises information that is obtained to improve their work for future occasions and reflects about the quality of it. 
We would like to point out some of the limitations of the research which we identify for future lines of study. On the one hand, as we previously explained in the methods section, the results we have obtained only make sense within the frame of the subjects analysed. Therefore it would be interesting to carry out similar research with a larger sample made up of different types of courses. On the other hand, taking into account the feedback conceptualisation proposed by Nicol (2011), other dimensions which define the feedback process could be analysed; for example, the forms of feedback proposed by Guasch et al. (2013): corrective, suggestive, epistemic, and informative and to analyse in-depth the consequences of the feedback provided through longitudinal studies.

To conclude, we want to emphasise that despite the evidence that peer-feedback has advantages for students, more student and teacher training should be given on this topic. The training in written feedback through digital tools should take into account the developing of strategies for providing teachers and students with knowledge and methodology on the type and characteristics of a good feedback, especially because of its potential to improve students' self-regulation skills and produce sustainable and long term learning.

\section{Endnotes}

${ }^{1}$ This research forms part of the innovative project: "Design, implementation and evaluation of sustainable feedforward experiences" (REDICE 2014-966), funded by University of Barcelona

Received: 13 September 2015 Accepted: 18 January 2016

Published online: 01 April 2016

References

Askew S, Lodge C (2000) Gifts, ping-pong and loops - Linking feedback and learning. In: Askew S (ed) Feedback for Learning. Routledge Falmer, London, pp 1-18

Biggs J (2003) Calidad del aprendizaje universitario. Cómo aprenden los estudiantes. Narcea, Madrid

Boud D, Molloy E (2013) Rethinking models of feedback for learning: the challenge of design. Assess Eval High Educ 38(6):698-712

Boud D (1995) Enhancing learning throught self assessment. Kogan Page, London

Brew (1999) Towards autonomous assessment: using self -assessment and peer assessment. In: Brown S, Glasner A (eds) Assessment matters in higher education: choosing and using diverse approaches. Society for Research into Higher education and Open University Press, Buckingham, pp 48-63

Carless D, Joughin G, Mok MMC (2006) Learning-oriented assessment: principles and practice. Assess Eval High Educ 31(4):395-398

Cheng W, Warren M (1999) Peer and teacher assessment of the oral and written tasks of a group project. Assess Eval High Educ 24(3):301-314

Dochy F, Segers M, Sluijsmans D (1999) The use of self-, peer- and co-assessment in higher education: A review. Studies in Higher Education 24:331-350

Falchikov N (2001) Learning together. Peer tutoring in higher education. Routledge Falmer, London

Giles A, Martin S, Bryce D, Hendry G (2004) Students as partners in evaluation: student and teacher perspectives. Assess Eval High Educ 29(6):681-685

Guasch T, Espasa A, Alvarez IM, Kirschner PA (2013) Effects of Teacher and Peer Feedback on Collaborative Writing in an Online Learning Environment. Distance education 34(3):324-338

Hounsell D (2007) Towards more sustainable feedback to students. In: Boud D, Falchilov N (eds) Rethinking assessment in higher education. Learning for the longer term. Routledge, London, pp 101-113

Jaques D (2000) Learning in groups: A handbook for improving group work, 3rd edn. Kogan Page, London

Kimbell R, Stables K (2008) Researching Design Learning. Springer, London

Lilly J, Richter M, Rivera-Macias B (2010) Using feedback to promote learning: student and tutor perspectives. Practitioner Research in Higher Education 4(1):30-40

Nicol D (2011) Good designs for written feedback for students. In: McKeachie WJ, Svinicki M (eds) McKeachie's Teaching Tips: Strategies, Research, and Theory for College and University Teachers, 13th edn. Wadsworth, Cengage Learning, Belmont USA, pp 108-124

Nicol D, MacFarlane-Dick D (2006) Formative assessment and self -regulated learning: A model and seven principles of good feedback practice. Studies in Higher Education 31(2):199-218

Orsmond P, Merry S, Reiling K (2000) The use of student-derived marking criteria in peer and self-assessment. Assess Eval High Educ 25(1):21-38

Patri M (2002) The influence of peer feedback on self- and peer assessment of oral skills. Language Testing 19(2):109-131

Ruegg R (2015) Differences in the Uptake of Peer and Teacher Feedback. RELC Journal 46(2):131-145 
Shute VJ (2008) Focus on formative feedback. Review of Educational Research 78(1):153-189

Simpson G, Clifton J (2015) Assessing postgraduate student perceptions and measures of learning in a peer review feedback process. Assessment \& Evaluation in Higher Education. 1-14. doi:10.1080/02602938.2015.1026874

Sluijsmans D, Brand-Gruwel S, Merriënboer J (2002) Peer assessment training in teacher education: Effects on performance and perceptions. Assess Eval High Educ 27(5):443-454

Strijbos J, Narciss S, Dünnebier K (2010) Peer feedback content and sender's competence level in academic writing revision tasks: Are they critical for feedback perceptions and efficiency? Learning and instruction 20(4):291-303

Topping K (1998) Peer assessment between students in colleges and universities. Review of Educational Research 68 . 249-276

Van Gennip NAE, Segers MSR, Tillema HH (2010) Peer assessment as a collaborative learning activity: the role of interpersonal variables and conceptions. Learning and Instruction 20(4):280-290

Wen M, Tsai C (2006) University students' perceptions of and attitudes toward (online) peer assessment. Higher Education 51:27-44

Wen M, Tsai C, Chang C (2006) Attitudes towards peer assessment: A comparison of the perspectives of pre-service and in-service teachers. Innov Educ Teach Int 43(1):83-92

Submit your manuscript to a SpringerOpen ${ }^{\circ}$ journal and benefit from:

- Convenient online submission

- Rigorous peer review

- Immediate publication on acceptance

- Open access: articles freely available online

- High visibility within the field

- Retaining the copyright to your article

Submit your next manuscript at $>$ springeropen.com 